\title{
Stress Analysis and Life Estimation of Gas Turbine Blisk for Different Materials of a Jet Engine
}

\author{
Madhu P \\ Assistant Professor, Department of Mechanical Engineering, Malnad College of Engineering, Hassan - 573202, Karnataka, India \\ Visvesvaraya Technological University, Belagavi - 590018, Karanataka, India
}

\begin{abstract}
The gas turbine is the heart of all modern aircraft. The role of the turbine blisk in a gas turbine is to expand the hot gases which come out from the combustion chamber and to provide the necessary thrust required, for the propulsion of the aircraft. Therefore the turbine blisk is the most critical part in a gas turbine engine. It also develops the power required to drive the compressor and other accessories. Three materials namely NI 90, MAR M 247 and IN 718 are being currently used for the manufacture of gas turbine blisk. These are nickel based super alloys. It is necessary to determine which among the three materials exhibit better fatigue life characteristics. In the present work a sector of the blisk (Bladed Disc) has been modeled using ANSYS 11.0 Finite Element Analysis software. The three different materials mentioned above are being considered for analysis, in the present study. Stress analysis has been carried out by the application of the boundary conditions and loads. The results obtained from the analysis have been used to determine the fatigue life and factor of safety by using relevant formulae. It is observed from the analysis that IN 718 has been found to exhibit better fatigue life characteristics.
\end{abstract}

Keywords: Blisk, Turbine, Superalloy, Fatigue Life, ANSYS

\section{Introduction}

A blisk (bladed disk) is a single engine component consisting of a rotor disk and blades, which may be integrally cast or machined from a solid piece of material or made by welding individual blades to the rotor disk. The term is used mainly in aerospace engine design. The word is a portmanteau of blade and disk, the two components it replaces in turbo machinery. Blisks may also be known as integrally bladed rotors (IBR). Blisk manufacturing has been used since the mid-1980s. It was first used by Sermatech-Lehr (now known as GKN Aerospace) in 1985 for the compressors of the T700 helicopter engine. Since then, its use has continued to increase in major applications for both compressors and fan blade rotors. Examples include the Rocketdyne RS-68 rocket engine and the General Electric F110 turbofan. The F-35B variant of the Joint Strike Fighter uses blisks to achieve STOVL. Engine manufacturer CFM International is using blisk technology in the compressor section of its Leap-X demonstrator engine program, which has completed full-scale rig testing. Power Jet SaM146 engines used on Sukhoi Superjet 100s are also equipped with blisks.

In the present work a turbine blisk has been used instead of a turbine rotor. The main purpose of selecting a blisk instead of a rotor is that the blisk is a single component consisting of both blade and disc whereas in rotor, the disk has to be made separately and blades are attached to it later which is a time consuming process and requires high manufacturing cost. But the turbine blisk reduces $75 \%$ of manufacturing cost. The aim of the work is to find out the maximum stress level experienced by the component and to estimate the life (Fatigue life of blisk) due to various loads (Inertia load, Thermal load \& Pressure load) applied on the component under severe engine operating conditions.

From the literature survey it is evident that there is an essential need for an efficient use of Finite Element Method
(FEM) technique so that accuracy of the result could be verified/ maintained for better analytical treatment. The objectives of the project are,

- To model a sector of a turbine blisk using ANSYS 11.0.

- To estimate the stresses experienced by the component by selecting three different materials.

- To discuss fatigue life estimation methods and to estimate the fatigue life theoretically.

- To choose the best material for future production of turbine blisk.

\section{Methodology / Approach}

The following methodology is adopted during present work,

- The literature review has been carried out to understand stress analysis of turbine rotors.

- The turbine blisk required for the analysis purpose has been modeled using 3D Finite Element Method created in ANSYS 11.0 software.

- After modeling of the turbine blisk, stress analysis has been carried out under various load conditions.

- Three different materials ie., NI 90, MAR M 247 and IN 718 have been selected for the purpose of analysis.

- Fatigue life $\left(\mathrm{N}_{\mathrm{f}}\right)$, for three different materials have been calculated theoretically by using Coffin-Manson Equation.

- The analytical results have been compared and the best material has been selected for future production of turbine blisk.

The 3D model of the blisk has been created using ANSYS. The sector of the blisk contains 10 numbers of blades. 


\section{International Journal of Science and Research (IJSR) \\ ISSN (Online): 2319-7064}

Index Copernicus Value (2013): 6.14 | Impact Factor (2015): 6.391

\section{Analysis}

The ANSYS 11.0 software was used for stress analysis of the turbine blisk. For all results, Megapascal (MPa) units were used to describe the fields of stress.

\section{For Material 1:}

NI-90

From figure 1 the maximum von mises stress induced in the blisk segment is found to be $557.198 \mathrm{Mpa}$ and acts at the bolt area of the disc for the operational speed of $29000 \mathrm{rpm}$. Also from figure 2 it can be seen that maximum von mises strain induced is 0.016629 . From figure 3 the maximum von mises stress induced in the blade area is found to be $339.72 \mathrm{Mpa}$ and acts at root of the blade where failure rate is more.

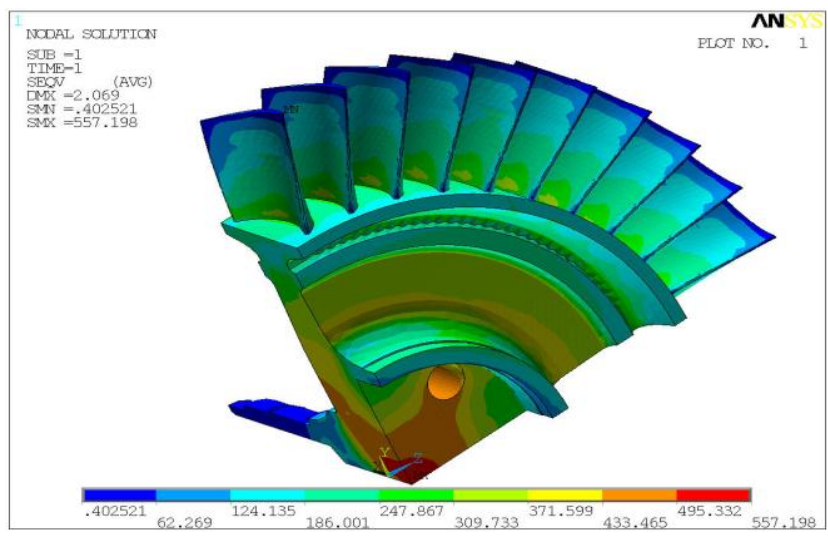

Figure 1: Von mises stress plot on blisk segment

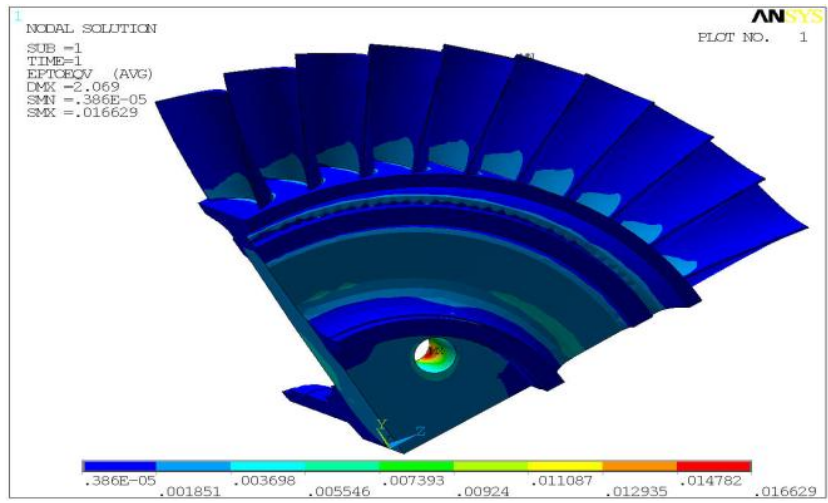

Figure 2: Von mises strain plot on blisk segment

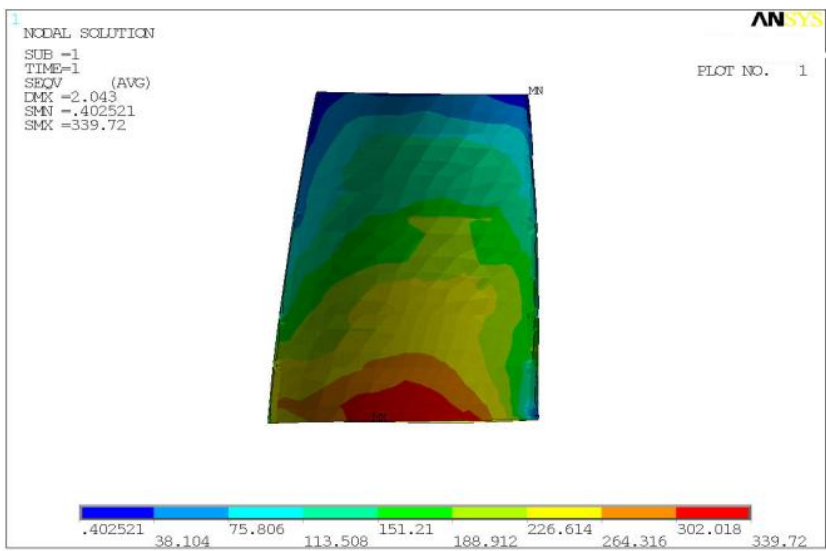

Figure 3: Von mises stress plot on blade
For Material 2:

MAR M 247

Figure 4 shows that the maximum von mises stress induced in the blisk segment is $761.774 \mathrm{Mpa}$ and acts at the bolt area of the disc for the operational speed of $29000 \mathrm{rpm}$. Similarly from figure 5 the maximum von mises strain induced is found to be 0.007283 . It can be seen from figure 6 that maximum von mises stress induced at the blade area is $604.72 \mathrm{Mpa}$ and acts at root of the blade where failure rate is more.

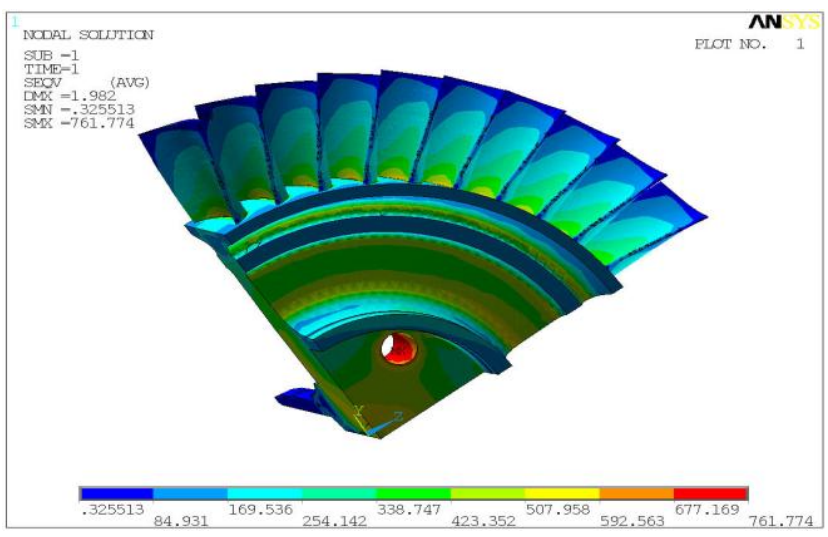

Figure 4: Von mises stress plot on blisk segment

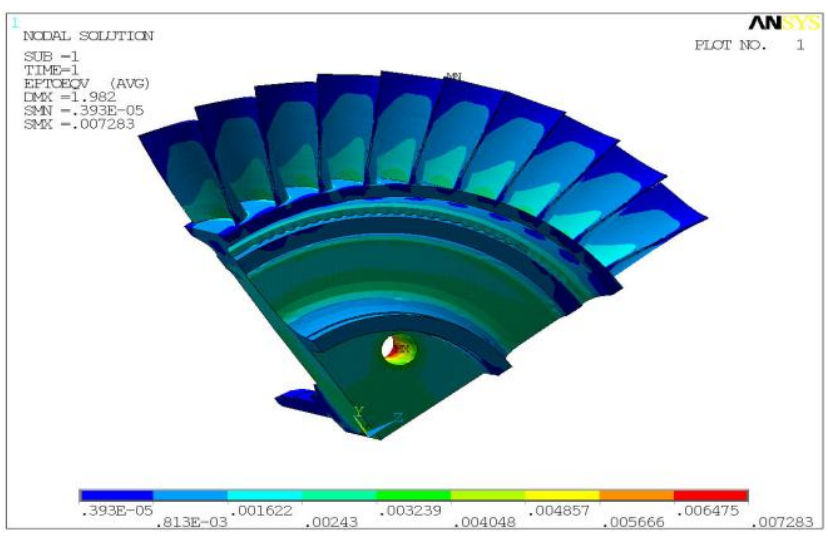

Figure 5: Von mises strain plot on blisk segment

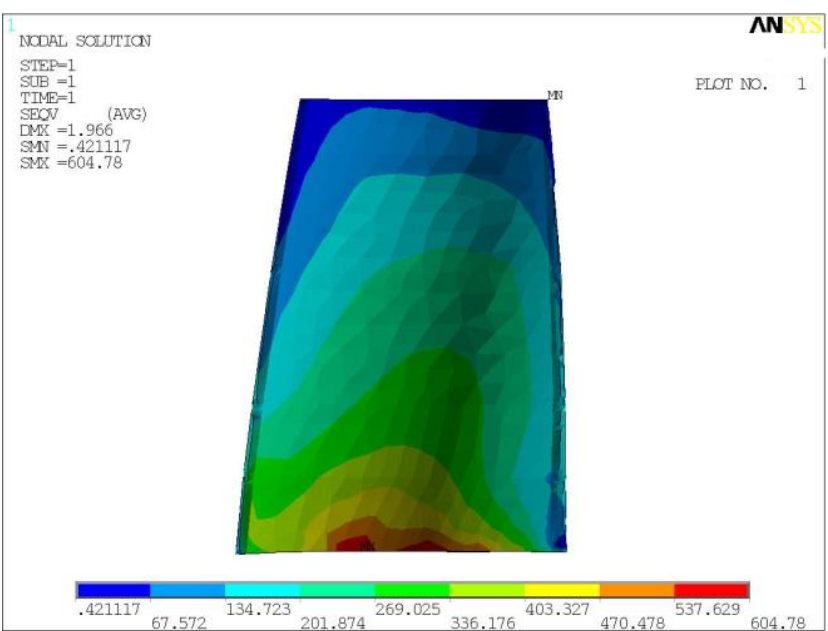

Figure 6: Von mises stress plot on blade 


\section{International Journal of Science and Research (IJSR) \\ ISSN (Online): 2319-7064}

Index Copernicus Value (2013): 6.14 | Impact Factor (2015): 6.391

\section{For Material 3:}

\section{IN 718}

It can be observed from figure 7 that the maximum von mises stress induced in the blisk segment is $731.772 \mathrm{Mpa}$ and acts at the bolt area of the disc for the operational speed of 29000 $\mathrm{rpm}$. Also from figure 8 it can be seen that the maximum von mises strain induced is 0.006681 . Figure 9 shows maximum von mises stress induced at the blade area is $477.735 \mathrm{Mpa}$ and it acts at root of the blade where failure rate is more.

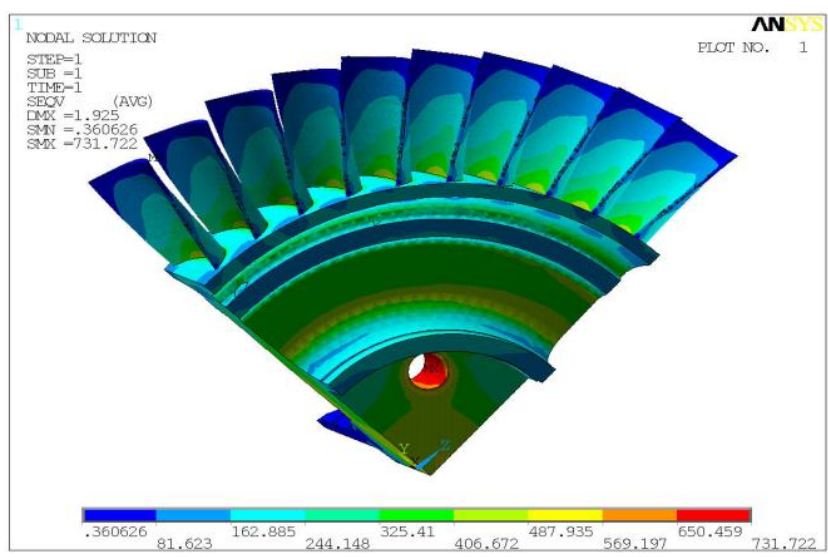

Figure 7: Von mises stress plot on blisk segment

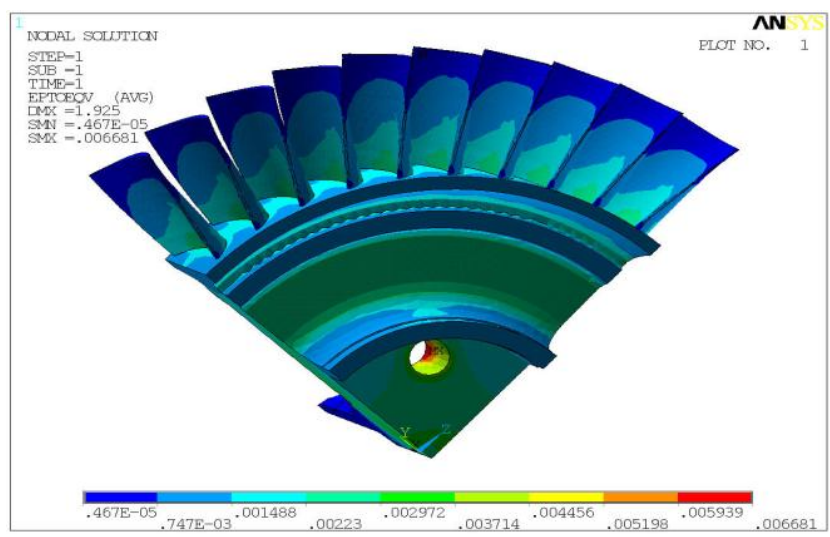

Figure 8: Von mises strain plot on blisk segment

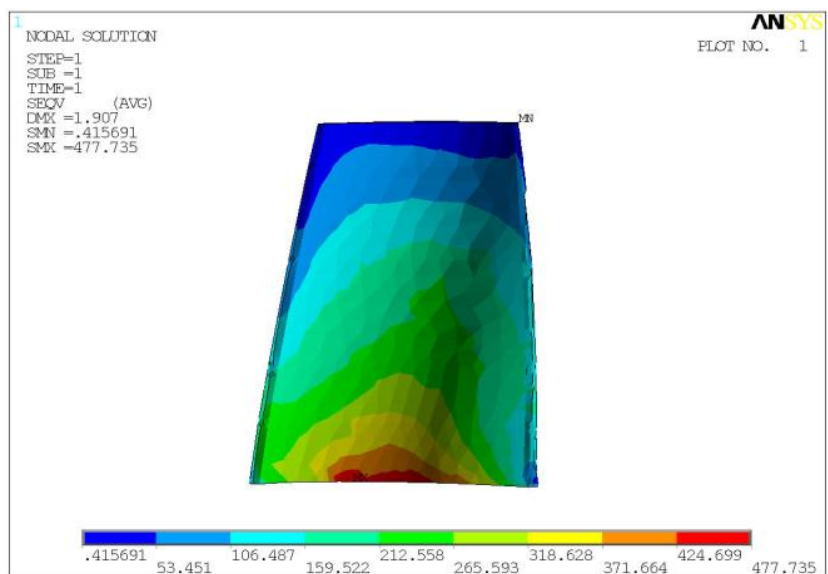

Figure 9: Von mises stress plot on blade

\section{Results and Discussion}

The stress analysis and fatigue life for the given materials have been carried out under maximum temperature and steady state conditions.

For all the three materials under consideration the operating speed of 29000 RPM has been kept constant.

From the above analysis it can be observed that the maximum working stress acts at the Bolt Area at temperature of $725^{\circ} \mathrm{C}$ and maximum von mises stress induced is within permissible limits for all the three materials considered.

The factor of safety has been determined by the following formula, Factor of safety = Yield Strength / Maximum Working Stress.

The fatigue life for the materials conducted has been obtained using Coffin-Manson Equation.

The fatigue life and factor of safety of all the materials have been determined as follows

\section{For Material 1,}

NI-90

Factor of safety, FOS $=580 / 557.198$

$=1.040$

Coffin Manson Eqn. is,

$$
\begin{aligned}
& \epsilon_{t}=\frac{3.5 * \mathrm{UTS}}{\mathrm{E}} \mathrm{N}_{\mathrm{f}}^{-0.12}+\mathrm{D}_{\mathrm{t}}^{0.6} * \mathrm{~N}_{\mathrm{f}}^{-0.6} \\
& D_{t}=-\ln (1-R A)
\end{aligned}
$$

Where,

UTS is Ultimate Tensile Strength

RA is Reduction of Area

E is Young's Modulus

$\epsilon_{t}$ is Total Mechanical Strain

$\mathrm{N}_{\mathrm{f}}$ is Number of Fatigue Cycle

$D_{t}$ is Ductility

Data:

$\mathrm{UTS}=816 \mathrm{MPa}$ at $\mathrm{T}=725^{\circ} \mathrm{C}$

$\mathrm{E}=15300 \mathrm{MPa}$ at $\mathrm{T}=725^{\circ} \mathrm{C}$

$\mathrm{RA}=12 \%$ at $\mathrm{T}=725^{\circ} \mathrm{C}$

$\epsilon_{t}=0.016629$

\section{Solution:}

Ductility, $D_{t}=-\ln (1-R A)$

$=-\ln (1-0.12)$

$=0.12783372$

Substituting the known values in the Coffin Manson Eqn. we get,

$\mathrm{N}_{\mathrm{f}}=8461$ Cycles

\section{For Material 2,}

MAR-M-247

Factor of safety, FOS $=800 / 761.774$

$=1.050$ 


\section{International Journal of Science and Research (IJSR) \\ ISSN (Online): 2319-7064}

Index Copernicus Value (2013): 6.14 | Impact Factor (2015): 6.391

\section{Data:}

$\mathrm{UTS}=1002 \mathrm{MPa}$ at $\mathrm{T}=725^{\circ} \mathrm{C}$

$\mathrm{E}=171250 \mathrm{MPa}$ at $\mathrm{T}=725^{\circ} \mathrm{C}$

$\mathrm{RA}=12 \%$ at $\mathrm{T}=725^{\circ} \mathrm{C}$

$\epsilon_{t}=0.007283$

\section{Solution:}

Substituting the known values in the Coffin Manson Eqn. we get,

$\mathrm{N}_{\mathrm{f}}=13444$ Cycles

\section{For Material 3,}

IN-718

Factor of safety, FOS $=852 / 731.72$

$$
=1.164
$$

\section{Data:}

$\mathrm{UTS}=933 \mathrm{MPa}$ at $\mathrm{T}=725^{\circ} \mathrm{C}$

$\mathrm{E}=156680 \mathrm{MPa}$ at $\mathrm{T}=725^{\circ} \mathrm{C}$

$\mathrm{RA}=12 \%$ at $\mathrm{T}=725^{\circ} \mathrm{C}$

$\epsilon_{t}=0.006681$

\section{Solution:}

Substituting the known values in the Coffin Manson Eqn. we get,

$\mathrm{N}_{\mathrm{f}}=29258$ Cycles

The results of the FEM analysis for the three different materials considered has been tabulated in table 1

Table 1: Results of three materials

\begin{tabular}{|c|c|c|c|}
\hline RPM & 29000 & 29000 & 29000 \\
\hline Material & NI-90 & $\begin{array}{c}\text { MAR-M- } \\
247\end{array}$ & IN-718 \\
\hline Max. working stress, in Mpa & 557.198 & 761.774 & 731.72 \\
\hline Max. Strain & 0.016629 & 0.007283 & 0.006681 \\
\hline Temp. at max. working stress & 725 & 725 & 725 \\
\hline $\begin{array}{c}\text { Yield Strength at } 725^{\circ} \text { C, in } \\
\text { Mpa }\end{array}$ & 580 & 800 & 852 \\
\hline $\begin{array}{c}\text { Ultimate Tensile Strength at } \\
\text { 725 }{ }^{\circ} \text { C, in Mpa }\end{array}$ & 816 & 1002 & 933 \\
\hline Factor of Safety & 1.040 & 1.050 & 1.164 \\
\hline Fatigue Life, cycles & 8461 & 13444 & 29258 \\
\hline
\end{tabular}

\section{Conclusion}

The main aim of the project has been to select the best material which has better fatigue life among the three materials viz NI 90, MAR M 247 and IN 718 considered for the future production of the turbine blisk. To achieve this, a model of turbine blisk has been created using ANSYS and later the stress analysis has been carried out.

The following conclusions have been drawn from the analysis,

- It is evident from the results of analysis that under given speed (which is around 29000 RPM), temperature and geometry, the stresses induced in the component are within the permissible limits for all the three materials.
- The maximum von mises stress induced has been lesser than the yield strength which suggests that the design is safe for all the three materials.

- The maximum stress level experienced, factor of safety and fatigue life cycle of the blisk under various loads at given temperature and speed, are better for IN-718 compared to NI 90 and MAR M 247.

- The Factor of safety (FOS) and fatigue life cycle $\left(\mathrm{N}_{\mathrm{f}}\right)$ of IN 718 has been found to be 1.164 and 29258 cycles respectively.

Hence it is concluded that IN 718 is a better material when compared to NI 90 and MAR M 247 and can be used for future production and applications of turbine blisk.

\section{Future Scope}

For the given model the stresses may be analyzed by making following changes,

1. The fillet radius between the blade and the disc may be increased optimally to minimize stress concentration effect near the blade root.

2. Thermal analysis can be carried out and the results can be used as an input for stress analysis instead of applying temperature gradient, which will give closer results.

3 . The above analysis can also be performed by considering other nickel based super alloys.

\section{Acknowledgement}

The project work was successfully carried out at HAL, Bangalore. I would like to thank Mr. D. Rajan, Deputy Manager, Methods Department, Engine Division, Mr. V. Reddy, Senior Manager, ETBRDC, Engine Division, HAL, Bangalore and Dr. L. Krishnamurthy, Professor, The National Institute of Engineering, Mysore for their valuable suggestions and guidance during my completion of project work at HAL Bangalore.

\section{References}

[1] Lucjan Witek, "Failure Analysis of turbine disc of an aero engine", Science Direct, Elsevier, 2006.

[2] M Mohammed Mohaideen, "Optimization and Analysis on turbine rotor of a turbo shaft engine", SciVerse Science Direct, Elsevier Ltd, 2012, p. 868.

[3] Ellie Zolfagharifard, "Rolls-Royce's Lift System for the Joint Strike Fighter", The Engineer 28 March 2011.

[4] Optioning the Future, Aviation Week \& Space Technology, 170, 10 (9 March 2009), p. 37.

[5] Bill Burchell, "Powering Up Next-Gen Engine MRO"Aviation Week, 2 November 2010.

[6] O. Younossi, et al., Military Jet Acquisition: Technology Basics and Cost-Estimating Methodology, RAND Corporation, ISBN 0-8330-3282-8, p. 29-30 (2002).

[7] John Croft, "NBAA: GE TechX fan blisk is all the buzz" Flightglobal, 21 October 2010.

[8] Homeshwar G Nagpure et.al. /, "Analysis of Stresses in Turbine Rotor Using Finite Element Method (FEM)", International Journal of Engineering Science and 
Technology (IJEST), Vol 4, March 2012, p. 1037, ISSN: 0975-5462.

[9] G Sukhvinder Kaur Bhatti, Shyamala Kumari, M L Neelapu, C Kedarinath, Dr. I N Niranjan Kumar, "Transient State Stress Analysis On An Axial Flow Gas Turbine Blades And Disk Using Finite Element Procedure". in Int. Conf. on HEAT TRANSFER, THERMAL ENGINEERING and ENVIRONMENT, Elounda, Greece, August 21-23, 2006 (pp323-330).

[10]Zvonimir Guzović, Branimir Matijašević, Tihomir Mihalić "Characteristics of Non- Stationary Thermal Stresses in the Low-Pressure Part of the Rotor"15th International Research/Expert Conference TMT-2011, Prague, Czech Republic 12-18 September 2011.

[11] Sudheendra V S, S Ramamurthy, K Murugesan, "Transient, Thermal Analysis of A Turbine Rotor"nalir.nal.res.in/8928.

[12]R. Nagendra Babu, K. V. Ramana, and K. Mallikarjuna Rao, "Determination of Stress Concentration Factors of a Steam Turbine Rotor by FEA" World Academy of Science, Engineering and Technology 392008 Homeshwar G Nagpure et al. / International Journal of Engineering Science and Technology (IJEST).

[13] Rolls Royce plc, "The Jet Engine", $5^{\text {th }}$ edition, Technical Publications Department Rolls Royce plc, Derby, England, ISBN 0-902121-2-35.

[14] Irwin E Treager, "Aircraft Gas Turbine Technology", $3^{\text {rd }}$ edition, McGraw-Hill Publishers, ISBN 13:9780028018287.

[15] David V Hutton, "Fundamentals of Finite Element Analysis", McGraw-Hill Inc. 1221, 2004.

[16] Tirupathi R Chandrupatla, Ashok D Belegundu, "Introduction to Finite Elements in Engineering", $4^{\text {th }}$ edition, Pearson education, January 2012.

[17] S S Rao, "The Finite Element Method in Engineering", $4^{\text {th }}$ edition, Elsevier, 2006.

[18] ANSYS "User's manual ", version 10 and 11.

[19] Kim W H, Laird, C. (1978), "Crack Nucleation and State I Propagation in High Strain Fatigue- II Mechanism", Acta Metallurgica. p. 789-799.

[20] Stephens, Ralph I.; Fuchs, Henry O. (2001). Metal Fatigue in Engineering (Second edition ed.). John Wiley \& Sons, Inc. p. 69. ISBN 0-471-51059-9.

[21] George E Dieter, "Mechanical Metallurgy", $3^{\text {rd }}$ edition, McGraw Hill Book Company.

[22] Hoppin G S, Danesi W P, "Manufacturing Processes for Long- Life Gas Turbines", Journal of metals, July 1986.

[23] Department of Defense Technical Monitoring by Army Materials and Mechanic Research Centre Watertown, "Aerospace structural metals handbook"

\section{Author Profile}

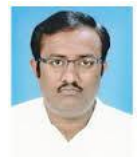

Madhu $\mathbf{P}$ received his $\mathrm{BE}$ in Mechanical Engineering and M.Tech in Product Design and Manufacturing from VTU University, Belagavi during the period $2008-2013$. Presently working as Assistant Professor in the Department of Mechanical Engineering, Malnad College of Engineering, Hassan. 